\title{
CONFLICTOS POR RECURSOS HÍDRICOS INTERPROVINCIALES Y TUTELA AMBIENTAL. EL CASO DE LA SALINIZACIÓN DEL RIO COLORADO EN EL SUR BONAERENSE
}

\author{
María de las Nieves Cenicacelaya ${ }_{* * *}^{*}$ \\ Carlos Gonzalo Francisco Fuentes"
}

\begin{abstract}
RESUMEN
La Constitución Argentina establece que las provincias son dueñas de sus recursos naturales pero también que cuando éstos son interprovinciales es necesario que su uso y aprovechamiento sea acordado entre las partes; y, finalmente cuando esos acuerdos fracasan, es la Corte Suprema la que debe resolver el conflicto. Los desacuerdos entre las provincias muy frecuentemente suceden por el uso y aprovechamiento de aguas inter-jurisdiccionales. En este trabajo abordaremos el caso de la salinización del Río Colorado, que, como consecuencia del obrar unilateral e inconsulto de la Provincia de La Pampa puede producir graves e irreparables daños al ambiente en el sur de la Provincia de Buenos Aires y que ha provocado recientemente un juicio entre ambas en el más alto tribunal federal.
\end{abstract}

PALABRAS ClAVES: Recursos Hídricos - Federalismo - Ambiente - Río Colorado

\begin{abstract}
Argentine Constitution provides that provinces are the owners of natural resources found on their lands, but it also states that the use and development of interprovincial resources must be agreed between all interested parties; and, at last, if no agreement is reached, the conflict must be resolved by Federal Supreme Court. Often, interprovincial conflicts are caused by the use and development of inter-jurisdictional waters. In this paper we report on the case of the salinization of Colorado River. This happens as a consequence of the unilateral and unconsulted action of La Pampa
\end{abstract}

\footnotetext{
* Profesora de Derecho Constitucional, FCJyS - UNLP.

** Profesor de Derecho Público Provincial y Municipal, FCJyS - UNLP.
} 
province. In so doing, serious and irreparable environmental damages can be caused in southern Buenos Aires. That has recently resulted in a trial case in the federal Supreme Court.

KEYWORDS: Water Resources - Federalism - Environment - Colorado River

\section{INTRODUCCIÓN}

La Constitución argentina - implícitamente en su versión original y de manera expresa a partir de la reforma de 1994 - ha establecido en su artículo 124 que las provincias ejercen el dominio de sus recursos naturales; entre los que se incluyen, claro está, los cursos de agua. Sin embargo, cuando éstos son compartidos con otras provincias, las entidades de la federación que se hallen involucradas deberán arreglar su uso y aprovechamiento a través de tratados interprovinciales, celebrados conforme al artículo 125 de la norma suprema.

En varias ocasiones, las provincias han recurrido a esta herramienta que ha resultado un medio idóneo para la gestión de las aguas inter-jurisdiccionales. En otras, sin embargo, el instrumento apuntado no ha logrado el éxito esperado.

También, como novedad, luego de la última reforma constitucional se ha incorporado el artículo 41, que tutela el ambiente $\mathrm{y}$ en el que, entre otras previsiones, se ha establecido para las autoridades un deber especial de cuidado y protección del mismo.

En este trabajo nos ocuparemos especialmente de uno de los conflictos interprovinciales desatados por el uso de recursos hídricos compartidos en el que está en juego la sostenibilidad ambiental de una zona del sur bonaerense y que, aunque de larga data, en los últimos tiempos ha recobrado actualidad debido a que se le ha solicitado a la Corte Suprema de Justicia de la Nación que alcance una solución aceptable para todas las partes de esta disputa.

$\mathrm{Si}$ bien la confrontación incluye a varias provincias, pondremos énfasis en la compleja situación que se vive en el Valle Bonaerense del Rio Colorado como consecuencia de la salinización de las aguas de este río por efecto del incorrecto uso y aprovechamiento de la cuenca Desaguadero - Salado - Chadileuvú Curacó y la falta de obras necesarias que evitarían los - entre otros enormes efectos nocivos que ello puede acarrear al ambiente de la 
región; y que motivara que a fines de 2016 la Provincia de Buenos Aires accionara judicialmente contra la Provincia de La Pampa ante el más alto tribunal del país.

\section{CONFLICTOS POR RÍOS INTER-JURISDICCIONALES}

La Constitución Argentina de 1853 adoptó el federalismo (artículo $1 \mathrm{CN}$ ) como forma de estado basándose en la Constitución de los Estados Unidos de 1787, aunque haciendo las necesarias adaptaciones a la realidad autóctona. En nuestro modelo, las entidades integrantes de la federación, aunque conserven el nombre de provincias, siguiendo el antecedente hispano, son auténticos estados autónomos en la medida en que crean su propio derecho, aunque con ciertas limitaciones que se derivan de la supremacía del ordenamiento jurídico federal por sobre los respectivos ordenamientos jurídicos locales (artículos 5, 31 y $123 \mathrm{CN}$ ).

En ese diseño constitucional las provincias ejercen un haz de competencias exclusivas, entre las que destacamos - sobre todo a partir de 1994, cuando por primera vez el texto supremo expresamente se pronunció al respecto - el dominio de los recursos naturales existentes en su territorio; y dentro de ellos, en lo que a este trabajo concierne, sus cursos de agua. Así, el dominio de los ríos, sean ellos navegables o no navegables, e independientemente de que estén situados en la totalidad de su curso dentro de una provincia, o transcurran por más de una provincia o sirvan de límite entre provincias, es, en todos los casos, provincial; y son las provincias quienes pueden decidir exclusivamente sobre la utilización y el aprovechamiento de esos ríos dentro de su territorio.

Sin embargo, lo anterior puede acarrear conflictos de difícil resolución; por ejemplo, si una provincia situada aguas arriba hiciera un uso desmedido del recurso hídrico, pudiendo llegar a despojar, incluso, a la provincia aguas abajo de la posibilidad de uso alguno; o si el curso fuese contaminado en la provincia aguas arriba y ello provocara luego daños en la provincia aguas abajo. Ahora bien, en razón del comportamiento cooperativo y solidario que el texto supremo nacional ordena a las provincias todas ellas deben, en lo que respecta a sus ríos compartidos, procurar un uso equitativo y razonable de los mismos (CENICACELAYA y PASTORINO, 2014, p. 107) 
A su turno, la misma Constitución Nacional dispone de una herramienta que puede resultar de suma utilidad para que las entidades de la federación puedan acordar sobre el particular, del mismo modo que el Derecho Internacional lo hace para el caso de los ríos transfronterizos, cuyas pautas pueden ser aplicadas analógicamente (BARBERIS, 1973, p. 263), como hace tres décadas dijo la propia Corte Suprema. ${ }^{1}$ Nos referimos a los tratados interprovinciales que prevé el artículo $125 \mathrm{CN}$ los que, deben ser puestos en conocimiento del Congreso Nacional - sin que éste tenga que prestar su consentimiento (QUIROGA LAVIÉ et. al. 2001, p. 1050) y que pueden colaborar a realizar la denominada concertación federal. (CENICACELAYA, 2014, p. 147)

En este sentido, en nuestro país, se han celebrado varios acuerdos interprovinciales en pos de consensuar la distribución, el manejo coordinado y la protección de las aguas compartidas. Y no obstante que no todos ellos presentan idénticas características, lo que sí tienen en común es la adopción del concepto de "cuenca", como área geográfica delimitada por la línea divisoria de aguas, que fluyen hacia un término común (MOYANO, 2014 p. 143) Ese es, además, el mecanismo recomendado desde la Subsecretaría de Recursos Hídricos de la Nación a efectos de acordar la distribución, el manejo coordinado y la protección de las aguas compartidas, en la medida que constituyen ámbitos propicios para la búsqueda anticipada de soluciones a potenciales conflictos. ${ }^{2}$

Y si ese conflicto se todas formas ocurriese, su resolución estará a cargo, también por mandato constitucional - artículo 127, 2da parte - de la Corte Suprema de Justicia de la Nación a través de la denominada jurisdicción "dirimente" o "diplomática" (MOYANO, 2014, p. 140) en la que el cimero tribunal actúa más como árbitro que como juez; donde, además, tiene amplias facultades para determinar el derecho aplicable ${ }^{3}$ y en la que tampoco es necesario que exista una contienda entre las provincias regulada por el derecho

\footnotetext{
${ }^{1}$ CSJN, La Pampa, Provincia de c/ Mendoza, Provincia de s/ acción posesoria de aguas y regulación de usos - 1987 - (Fallos 310:2478)

${ }^{2}$ SSRH, Principios Rectores de Política Hídrica (PRPH), Principios 22 y 23.

${ }^{3}$ CSJN, La Pampa, Provincia de c/ Mendoza, Provincia de s/ acción posesoria de aguas y regulación de usos - 1987 - (Fallos 310:2478)
} 
sino que basta que haya "quejas" de una contra otra o recíprocos reclamos (QUIROGA LAVIÉ et al., 2001, p. 1261)

No obstante que más del $90 \%$ de las aguas - excluyendo obviamente las marítimas - que discurren por el territorio nacional son interprovinciales (CANO, 1976, p. 494) hasta el momento sólo dos pleitos han sido dirimidos por el máximo tribunal federal: el conocido como caso "del Río Atuel", con motivo de la controversia por varias décadas entre las provincias de La Pampa y Mendoza sobre el aprovechamiento de esa sub cuenca hídrica, ${ }^{4}$ y otro que intentaba precautoriamente evitar daños mientras se resolvía la cuestión principal en torno a la modificación del escurrimiento natural de las aguas interprovinciales de la Laguna La Picasa ubicada entre el sudoeste de Santa Fe y el noroeste de Buenos Aires. ${ }^{5}$

\section{LA CUENCA DESAGUADERO-SALADO-CHADILEUVÚ- CURACÓ}

Esta cuenca es un sistema que se activa principalmente en los años en que hay importante acumulación de nieve o lluvia en la cordillera y cuando los excedentes de los ríos San Juan, Mendoza, Tunuyán y Diamante a fines del invierno derraman sus caudales en el Río Desaguadero que luego de atravesar la Provincia de San Luis entra a la de La Pampa, se une con el Atuel y forma así el Río Salado, luego de pasar por bañados y lagunas donde sus aguas se van salinizando. Continúa y se transforma en el Río Chadileuvú que pasa primero por un sector de lagunas y luego por los bajos del Curacó donde se recarga de sales. Desde allí sigue su curso hasta desembocar en el Río Colorado con una tan alta salinización que hace imposible su potabilización para consumo humano y su utilización para riego.

En 1976 las provincias de Buenos Aires, La Pampa, Mendoza, Neuquén y Río Negro en la VI Conferencia de Gobernadores acordaron el Programa Único de Habilitación de Áreas de Riego y Distribución de Caudales del Río Colorado estableciendo un límite

\footnotetext{
${ }^{4}$ Ibídem.

5 CSJN, Buenos Aires, Provincia de c/ Santa Fe, Provincia de s/ sumarísimo derivación de aguas - 2000 - (Fallos 323:1877)
} 
máximo de concentración salina en la entrada de la cuenca inferior en 1,8 mmhos $/ \mathrm{cm}$, acuerdo que fue ratificado por todas las provincias involucradas y por Estado Nacional. En simultáneo crearon el Comité Inter-jurisdiccional del Río Colorado (COIRCO) a fin de asegurar la ejecución del mencionado Programa.

En la década de 1980, con elevadas precipitaciones pluviales y níveas, se reactivó después de cuarenta años, el sistema Desaguadero-Salado-Chadileuvú-Curacó, volviéndose a conectar con el Río Colorado, generando un aumento en la cantidad de sales disueltas en las aguas de este último, lo que provocaría enormes daños en el sur de la Provincia de Buenos Aires. Concretamente, a mediados del decenio, la salinidad del agua llegó a 2,4 mmhos $/ \mathrm{cm}$, tornándola inviable para riego, de difícil potabilización para consumo humano, y sumamente dañina para la biodiversidad (HERNÁNDEZ, 2013, p. 19). Fue entonces cuando se empezó a pensar en una "solución" para este problema. 


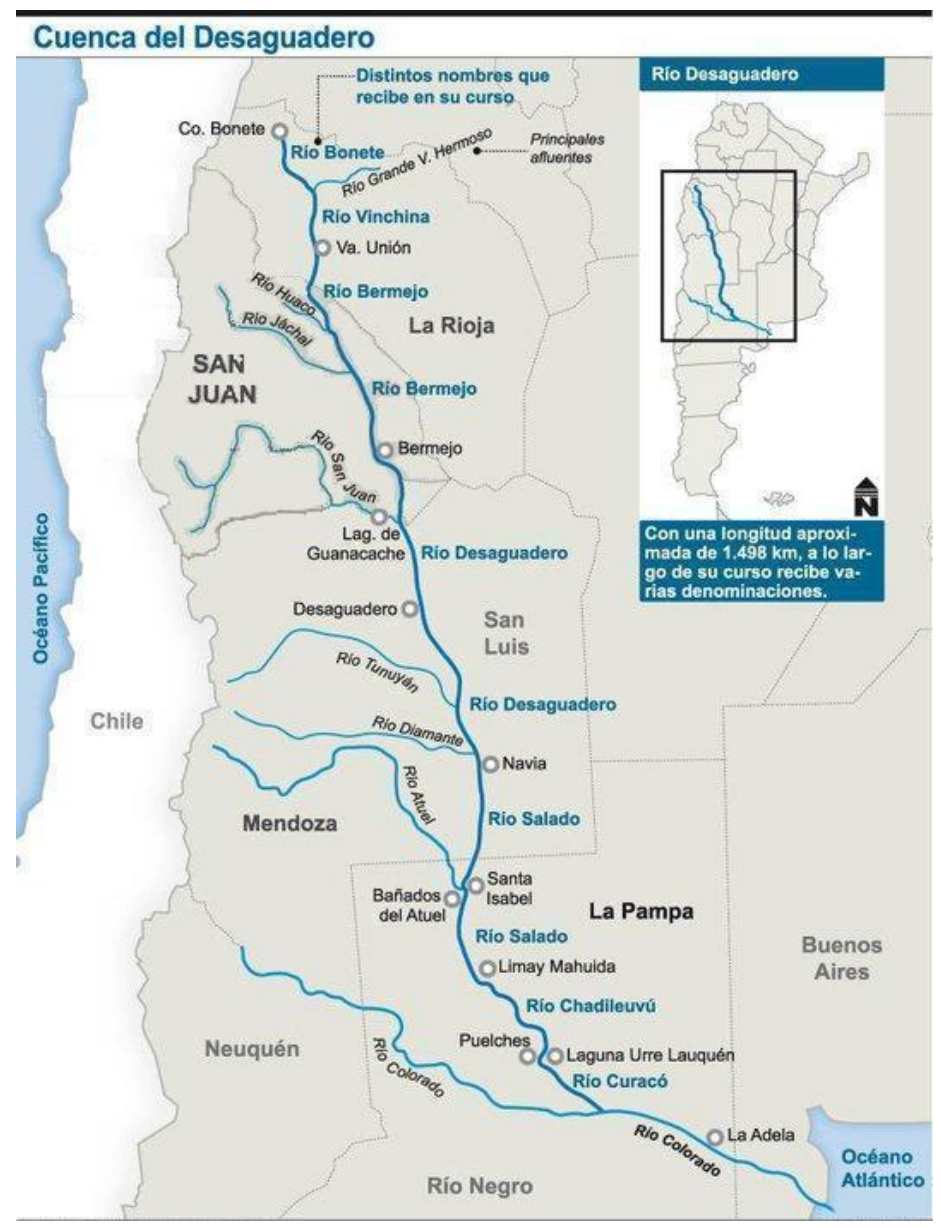

En el año 1985, los gobernadores de Buenos Aires, La Pampa y Río Negro suscribieron un Acta Acuerdo - luego ratificado por todas las legislaturas - por la que se consensuó realizar estudios, proyectos y obras tendientes a atenuar y/o controlar los aportes salinos de las aguas del Río Curacó al Río Colorado, entre ellas, obras de control de escurrimiento entre la Laguna La Amarga y el curso del Río Curacó y otras que pudieran resultar convenientes a los fines perseguidos. Y pocos días después ya se definía entre las obras de urgente realización, un terraplén de cierre de la vaguada de 
conexión entre el Río Curacó y sus bañados con la Laguna La Amarga, que aún no tenía nombre definido y que más tarde pasaría a denominarse "Tapón de Alonso" en alusión a Mauro Alonso, propietario del campo en el que se construiría. Durante todos los años que siguieron funcionó, además, un Alerta Hidrológico del Sistema Curacó, financiado por las tres provincias y coordinado por el COIRCO que llevaba - lleva - a cabo periódicamente los registros de alturas, caudales y determinaciones de conductividad (niveles de salinización) del Río Curacó.

La función del Tapón de Alonso es retener el agua en el último tramo de lagunas antes de encausarse el Río Curacó en sus finales 115 kilómetros hasta llegar al Río Colorado. Esa retención hace que se vaya llenando el bañado y escurra hacia la Laguna La Amarga. Dicho tapón es un dique construido en el río para evitar que sus aguas, de marcada salinidad, alcancen las aguas del Río Colorado, y, con ello, afecten miles de hectáreas en la Provincia de Buenos Aires. Precisamente para evitar ese daño, La Pampa ha aceptado "sacrificar" una importante cantidad de hectáreas a las cuales derivan las aguas saladas en caso de crecidas.

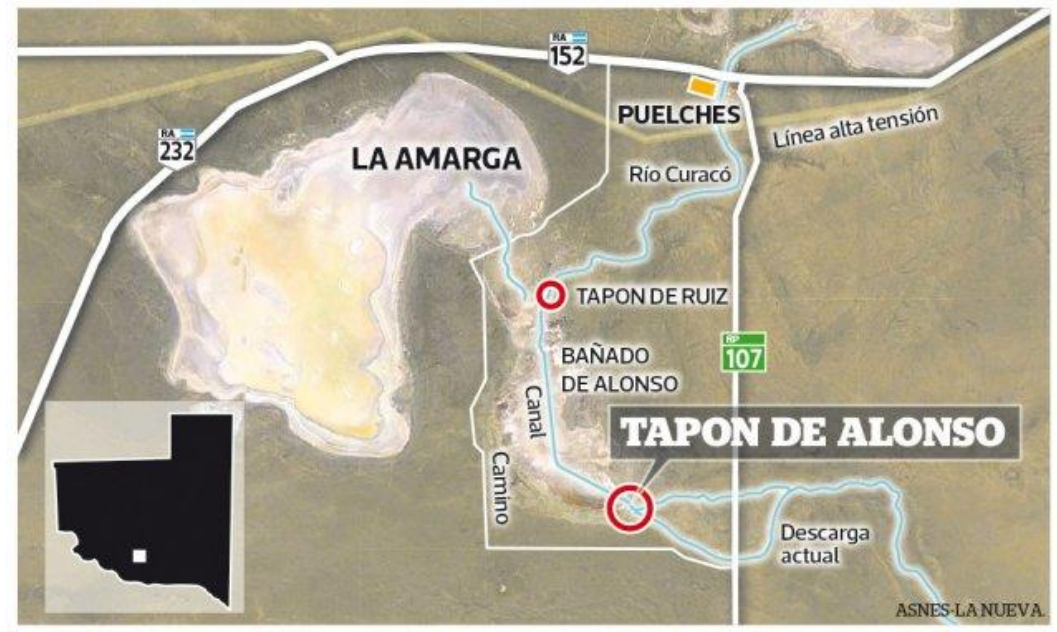

Este sistema funcionó mientras hubo gran disponibilidad de agua. Pero al comenzar el ciclo de sequías, el gobierno pampeano 
decidió, en 2007, abrir las compuertas para que los ganaderos de la zona, pudieran abrevar su ganado, argumento que la Provincia de Buenos Aires pone en duda por entender poco factible que los animales pudiesen beber esa agua de tenor salino tan alto. ${ }^{6}$

De este modo, el agua salada volvió a llegar al Río Colorado afectando sobre todo al sur bonaerense. A continuación, a instancias de Buenos Aires, se realizaron algunas obras para lograr una mayor dilución de las sales y mantener la salinidad por debajo de 1,2 mmhos/cm, y se colocaron tres caños con compuertas para poder regular descargas menores para abastecer de agua al ganado pampeano, evitando a la vez que llegara el agua salada al Río Colorado.

Para sostener su decisión, La Pampa alegaba que la solución para que no llegue agua salina al Río Colorado no podía ser cortar otro río y dejar esa agua en su territorio, sino que había que regular los caudales para que no entren excesos esporádicos desde las provincias de Mendoza y San Juan en suelo pampeano. En este punto es necesario recordar que aquélla provincia reclamó por años la creación de un organismo de cuenca que se ocupe de la problemática generada por el aprovechamiento inconsulto de las provincias aguas arriba de los caudales del sistema con la finalidad de contar con un caudal mínimo que permitiera, además de abastecer de agua al ganado, también generar un corredor húmedo en el medio de un área semidesértica con el consiguiente beneficio para la región (REGAZZOLI Y MECA, 2013). No habiendo tenido éxito en este propósito, el pasado año se presentó a la justicia para reclamar la conformación del Comité de Cuenca del Desaguadero-SaladoChadileuvú-Curacó. ${ }^{7}$

Hasta 2016, debido a la crisis hídrica que afectó a los todos los ríos cordilleranos, no volvió a llegar agua al Tapón de Alonso. Pero ese año los ríos mendocinos aumentaron su caudal - en relación a la media histórica - como consecuencia de un ciclo nivológico rico, comenzando a generarse excedentes en la cuenca y una mayor

$6 \quad$ http://www.eldiariodelapampa.com.ar/index.php/110-portada/secundario/19737buenos-aires-fue-a-la-corte-suprema-por-el-tapon-de-alonso Acceso en 19 abr. 2017

${ }^{7}$ CSJN 1055/2016 Originario. La Pampa, Provincia de c/ Estado Nacional s/ amparo - comité de cuencas. 
salinización del agua del Río Curacó que vuelca en el Río Colorado, uno de los más importantes de Argentina y de la Patagonia en particular. Su longitud es de $1.114 \mathrm{~km}$, de los cuales $500 \mathrm{~km}$ ponen límite a La Pampa y Río Negro, para luego atravesar el sur de Buenos Aires y desaguar en el Atlántico.

El nivel de salinidad del Curacó es del orden de los $10 \mathrm{gr} / \mathrm{lt}$. de salinidad mientras que el agua de mar tiene 3,5 gr/lt, lo que implica que es un río que transporta tres veces la salinidad del agua de mar. Es por ello que la descarga de agua con tan alto contenido de sales en el Río Colorado, importa la pérdida de este último como recurso hídrico: no sólo que deteriora los suelos y deja de ser posible su uso con fines de riego, sino que además resulta imposible su potabilización para consumo humano.

El Valle Bonaerense de este río se ubica al sudoeste de la Provincia de Buenos Aires sobre los municipios de Villarino y Patagones cuyas localidades más importantes totalizan unos 40.000 habitantes. Cuenta con un total de 530.000 hectáreas, de las cuales un tercio se encuentran sistematizadas bajo riego. Sus suelos son muy variados, predominando los arenosos, lo que permite una amplia gama de cultivos. El 76,2\% de su Producto Bruto Agropecuario proviene de la agricultura (trigo, maíz, girasol, avena, sorgo, cebada y centeno) Además, el Valle es el principal productor nacional de cebolla. ${ }^{8}$ El continuo riego con agua salada - aún en baja concentración - provoca la permanente acumulación de sal en la tierra, la que con el tiempo se saliniza, mermando la fertilidad del suelo, bajando su productividad y pudiendo llegar al colapso. Además, la salinidad del agua afecta también a la vegetación y fauna silvestre de la zona ya que el incremento de algunos cationes indeseables que aquélla conlleva - como el sodio - posee efectos tóxicos para la biodiversidad (IURMAN, ARAGÓN, SÁNCHEZ Y ANCIA, 2007) ${ }^{9}$

\footnotetext{
${ }^{8}$ http://www.corforiocolorado.gov.ar

${ }^{9}$ Iurman, Daniel, Aragón, Marcos, Sánchez, Ramón y Ancia, Virginia. Variables a considerar para una estimación de las pérdidas económicas por causa de la salinización del Río Colorado y su cuantificación. CORFO Río Colorado - INTA Estación Experimental Agropecuaria Hilario Ascasubi - Ministerio de Agricultura, Ganadería y Pesca, 2007
} 


\section{TUTELA DEL AMBIENTE}

A partir de la década de 1970, ante la comienza en el mundo la toma de conciencia del grave deterioro ambiental del planeta, y empieza también a abrirse camino en las constituciones la consagración de los derechos ambientales derechos como fundamentales. Por razones obvias, la Constitución argentina de 1853 no previo norma alguna relativa a la cuestión ambiental, no obstante que la cláusula de los derechos implícitos (artículo $33 \mathrm{CN}$ ) permitía darles cobertura. Más recientemente, la reforma de 1994 otorgó una amplia tutela a los derechos ambientales en diversas normas, pero centralmente en el artículo $41 \mathrm{CN}$, operando como matriz de todos los demás derechos fundamentales, debiendo orientar todas las formas de actuación de los poderes públicos y de los particulares (QUIROGA LAVIÉ et al., 2001, p. 323)

En su primer párrafo la citada norma establece que "Todos los habitantes gozan del derecho a un ambiente sano, equilibrado, apto para el desarrollo humano y para que las actividades productivas satisfagan las necesidades presentes sin comprometer las de las generaciones futuras; y tienen el deber de preservarlo", obligación que se reitera - específicamente en el segundo párrafo - para las autoridades (nacionales, provinciales y municipales, ejerzan funciones administrativas, legislativas o judiciales) quienes tienen, entre otras obligaciones, que proveer a la "utilización racional de los recursos naturales, a la preservación del patrimonio natural y cultural y de la diversidad biológica".

A su turno, en el tercer párrafo se consigna que le "corresponde a la Nación dictar las normas que contengan los presupuestos mínimos de protección, y a las provincias, las necesarias para complementarlas". De esta forma se impone en materia ambiental una uniformidad relativa o mínima en todo el país aceptándose el complemento original e innovativo de cada legislación local, siempre que respete el "piso" mínimo.

Hasta el momento, el Congreso nacional ha adoptado una decena de esas leyes, entre ellas, la 25.675, Ley General del Ambiente y otras sectoriales, como, por ejemplo, la Ley 25.688 sobre el Régimen de Gestión Ambiental de las Aguas.

La primera, que establece los presupuestos mínimos para el logro 
de una gestión sustentable y adecuada del ambiente, la preservación y protección de la diversidad biológica y la implementación del desarrollo sustentable (artículo 1) señala entre sus objetivos, asegurar la preservación, conservación, recuperación y mejoramiento de la calidad de los recursos ambientales; promover el mejoramiento de la calidad de vida de las generaciones presentes y futuras, en forma prioritaria así como el uso racional y sustentable de los recursos naturales; mantener el equilibrio y dinámica de los sistemas ecológicos; asegurar la conservación de la diversidad biológica; y prevenir los efectos nocivos o peligrosos que las actividades antrópicas generan sobre el ambiente para posibilitar la sustentabilidad ecológica, económica y social del desarrollo (artículo 2).

Además, en su artículo 4 consigna que su interpretación y aplicación - y la de toda otra norma a través de la cual se ejecute la política ambiental - estarán sujetas al cumplimiento de una serie de principios provenientes del Derecho Internacional, entre los que destacamos, en primer lugar: sustentabilidad (el desarrollo económico y social y el aprovechamiento de los recursos naturales deberán realizarse a través de una gestión apropiada del ambiente, de manera tal, que no comprometa las posibilidades de las generaciones presentes y futuras); equidad intergeneracional (los responsables de la protección ambiental deberán velar por el uso y goce apropiado del ambiente por parte de las generaciones presentes y futuras); cooperación (los recursos naturales y los sistemas ecológicos compartidos serán utilizados en forma equitativa y racional); solidaridad (la Nación y los estados provinciales serán responsables de la prevención y mitigación de los efectos ambientales transfronterizos adversos de su propio accionar, así como de la minimización de los riesgos ambientales sobre los sistemas ecológicos compartidos); y responsabilidad (el generador de efectos degradantes del ambiente, actuales o futuros, es responsable de los costos de las acciones preventivas y correctivas de recomposición). Estos principios de política ambiental son valiosas herramientas de interpretación para evaluar las conductas de autoridades y particulares en las etapas ex ante y ex post del daño ambiental, que la propia ley define como toda alteración relevante que modifique negativamente el ambiente, sus recursos, el equilibrio de los ecosistemas, o los bienes o valores colectivos (artículo 27). 
Pero también la Ley 25.675 incorpora el principio de prevención en el sentido de que las causas y las fuentes de los problemas ambientales se atenderán en forma prioritaria e integrada, tratando de prevenir los efectos negativos que sobre el ambiente se pueden producir; $y$, aún más, el principio precautorio que postula que cuando haya peligro de daño grave o irreversible la ausencia de información o certeza científica no deberá utilizarse como razón para postergar la adopción de medidas eficaces, en función de los costos, para impedir la degradación del medio ambiente (artículo 2). Así el concepto de daño ambiental ya no sólo se vincula al efectivamente causado en forma posterior a su acaecimiento sino también en relación al daño futuro posible (DI PAOLA, María Eugenia y MACHAIN, Natalia, p. 21)

En uno de los casos más emblemáticos de los últimos años, la Corte Suprema ha enfatizado que "La tutela del ambiente importa el cumplimiento de los deberes que cada uno de los ciudadanos tiene respecto del cuidado de los ríos, de la diversidad de la flora y la fauna, de los suelos colindantes, de la atmósfera. Estos deberes son el correlato que esos mismos ciudadanos tienen a disfrutar de un ambiente sano, para sí y para las generaciones futuras, porque el daño que un individuo causa al bien colectivo se lo está causando a sí mismo. La mejora o degradación del ambiente beneficia o perjudica a toda la población, porque es un bien que pertenece a la esfera social y trans-individual, y de allí deriva la particular energía con que los jueces deben actuar para hacer efectivos estos mandatos constitucionales". 10

Por su parte, la Ley 25.688 que establece los presupuestos mínimos ambientales para la preservación de las aguas, su aprovechamiento y uso racional, prevé que en el caso de las cuencas inter-jurisdiccionales, cuando el impacto ambiental sobre alguna de las otras jurisdicciones sea significativo, será el Comité de Cuenca correspondiente quien apruebe todo lo relativo a la utilización de esas agua. En tal sentido, el obrar unilateral e inconsulto de la Provincia de La Pampa, con la expresa oposición de los integrantes

\footnotetext{
${ }^{10}$ CSJN, Mendoza, Beatriz Silvia y otros c/ Estado Nacional y otros s/ daños y perjuicios (daños derivados de la contaminación ambiental del Río Matanza Riachuelo-2006- (Fallos 329:2316)
} 
del COIRCO, al abrir el Tapón de Alonso, configura una violación a esta norma.

\section{BUENOS AIRES VS. LA PAMPA}

A mediados de 2016, en una reunión del COIRCO, el representante de La Pampa informa que, como consecuencia de que algunas obras del Tapón de Alonso se encuentran parcialmente dañadas, aquél no cumpliría con su finalidad; pero también comunica que su provincia no está dispuesta a hacer las reparaciones del caso, sino, por el contrario, que se dejará escurrir el agua salina del Río Curacó hacia el Río Colorado, lo que fue objetado por los representantes de Buenos Aires y Río Negro que entendían que la decisión pampeana violaba acuerdos de larga data, poniendo en peligro el recurso hídrico. ${ }^{11}$

Posteriormente las autoridades pampeanas se comprometieron a restituir las compuertas. Pero ante la falta de medidas concretas por parte del gobierno de La Pampa, Gobernadora bonaerense decidió el inicio de una demanda contra aquélla provincia ${ }^{12}$ interponiendo una acción constitucional en los términos del artículo $127 \mathrm{CN}$ y, en subsidio, una acción de amparo para el eventual caso de que el cimero tribunal considerase no se diesen los extremos de la citada norma suprema. Además solicita una medida cautelar al entender que, de retrasarse el pronunciamiento judicial, podría generarse una situación de severo e irreparable perjuicio al verse afectado el ambiente y las personas con un gravamen de imposible reparación ulterior. $^{13}$

Cabe apuntar, por otra parte, que la Provincia de Río Negro adopta similar actitud al mes siguiente, demandando también a La Pampa, en similares términos a lo hecho por Buenos Aires. ${ }^{14}$

\footnotetext{
11 http://www.elcordillerano.com.ar/index.php/judiciales/item/42985-rio-negrorecurrio-a-la-suprema-corte-de-justicia-para-que-la-pampa-evite-la-salinizacion-delrio-colorado

12 Decreto 230/2016 y Resolución Delegada 90/2016

${ }^{13}$ CSJN 1381/2016 Originario. Buenos Aires, Provincia de c/ La Pampa, Provincia de s/ ordinario.

${ }^{14}$ CSJN 1462/2016 Originario. Río Negro, Provincia de c/ La Pampa, Provincia de s/ ordinario.
} 
La Provincia de Buenos Aires denuncia que la salinización de las aguas del Río Colorado es un fenómeno no habitual aunque previsible y dañino, que se debe, no a un hecho de la naturaleza, sino a la acción unilateral, intempestiva, ilegítima y arbitraria de la Provincia de La Pampa de evitar que el Tapón de Alonso cumpla la función para la cual fue creado y no derivar las aguas hacia la Laguna La Amarga, violando los acuerdos que obligan a las partes desde hace cuatro décadas, además de normas de Derecho Internacional Ambiental y del Derecho de los Cursos de Agua Internacionales que es aplicable, como dijimos, a los ríos interprovinciales en un Estado federal como el argentino. ${ }^{15}$

Como no se puede predecir los niveles de descarga del Río Curacó en el Río Colorado y existen los antecedentes de la década de 1980 cuando por los altos niveles de salinidad hubo que suspender el riego para evitar no sólo la pérdida de los cultivos sino también preservar el suelo, la Provincia de Buenos Aires entiende que es imprescindible tomar medidas inmediatas para evitar los temidos e irreversibles resultados. En efecto, si el agua salinizada del Río Curacó llegase al Río Colorado provocaría la elevación de los tenores salinos de este último alcanzando 1.95/2.15 mmhos/cm provocando daños a la salud humana de las poblaciones que se abastecen de dicha fuente para satisfacer sus necesidades más elementales, a la producción agrícola de la zona, y al ambiente del ecosistema en la calidad de su agua, su suelo y su biodiversidad.

En ese sentido, y apelando a los principios de prevención y precaución contemplados en la Ley General del Ambiente, solicita el dictado de una medida cautelar innovativa urgente, en los términos de la misma ley, ${ }^{16}$ consistente en ordenar a la Provincia de La Pampa restablecer las cosas al estado anterior procediendo al inmediato cierre del Tapón de Alonso a fin de hacer cesar el paso de agua del Río Curacó hacia el Río Colorado, y a realizar las acciones necesarias para impedir

\footnotetext{
${ }^{15}$ CSJN, La Pampa, Provincia de c/ Mendoza, Provincia de s/ acción posesoria de aguas y regulación de usos - 1987 - (Fallos 310:2478)

${ }^{16}$ Ley 25.675, artículo 32, 2do párrafo. - En cualquier estado del proceso, aun con carácter de medida precautoria, podrán solicitarse medidas de urgencia, aun sin audiencia de la parte contraria, prestando debida caución por los daños y perjuicios que pudieran producirse. El juez podrá, asimismo, disponerlas, sin petición de parte.
} 
que el caudal que escurre por el Río Curacó alcance al Río Colorado a fin de evitar la consumación de su contaminación; ello, luego de considerar probada la verosimilitud del derecho invocado y el peligro en la demora, y como medio idóneo para hacer efectivos los propósitos y fines perseguidos por el artículo $41 \mathrm{CN}$.

\section{CONSIDERACIONES FINALES}

En el diseño constitucional argentino, las provincias como entidades autónomas de la federación, ejercen el dominio de sus recursos naturales; entre ellos, sus ríos; y cuando éstos son compartidos con otras provincias, es necesario que acuerden a través de tratados interprovinciales acerca de su uso y aprovechamiento. Cualquier decisión inconsulta de alguna de ellas, habilita a la que se considere afectada, cierta o eventualmente, a presentar su queja ante la Corte Suprema de Justicia para que el más alto tribunal federal dirima el conflicto.

Eso ha hecho recientemente la Provincia de Buenos Aires denunciando que la Provincia de La Pampa, con su obrar unilateral de remoción de los obstáculos -construidos expresamente y con su anuencia- que impiden la llegada de aguas altamente salinizadas del Río Curacó al Río Colorado, ha puesto en serio riesgo ambiental a la zona del Valle Bonaerense del Río Colorado. De esta forma, las autoridades pampeanas han desconocido la obligación constitucional que les impone el artículo 41 de adoptar todas las medidas necesarias que resulten oportunas, adecuadas y efectivas en la medida que de ellos dependa, para evitar, impedir o mitigar la salinización de las aguas del río Colorado y así salvaguardar el ambiente y los recursos naturales de la zona.

Ante la amenaza ostensible, grave e inminente de daño sobre un bien de incidencia colectiva (el ambiente en general y un recurso hídrico, en particular) en aplicación de los principios de prevención y precautorio, la Corte Suprema de Justicia debería con toda celeridad tomar las medidas conducentes a fin de impedir que se concreten perjuicios irreparables. 


\section{REFERENCIAS}

ARGENTINA. Constitución de la Nación Argentina, 1994. Disponible en http://www.saij.gob.ar/nacional-constitucion-nacion-argentina-lnn00026651853-05-01/123456789-0abc-defg-g56-62000ncanyel Acceso en 27 abr. 2017

BARBERIS, Julio A. Fuentes del derecho internacional. La Plata: Editora Platense, 1973.

- Ley General del Ambiente, 25.675. Disponible en http://servicios.infoleg.gob.ar/infolegInternet/anexos/7500079999/79980/norma.htm Acceso en 24 abr. 2017

Disponible . Ley del Régimen de Gestión Ambiental de las Aguas, 25.688. http://servicios.infoleg.gob.ar/infolegInternet/verNorma.do?id=81032

en Acceso en 24 abr. 2017

CANO, Guillermo. Derecho Política y Administración de Aguas. Mendoza: INCyTH, 1976

CENICACELAYA, María de las Nieves. Los recursos hídricos interprovinciales y el federalismo argentino. In Congreso Internacional De códigos y desafíos jurídicos para enfrentar la crisis del agua, Facultad de Ciencias Jurídicas y Sociales, Universidad Nacional de La Plata. Buenos Aires: Ediciones Cooperativas, 2014.

CENICACELAYA, María de las Nieves; PASTORINO, Leonardo Fabio. Cursos de agua compartidos en el federalismo argentino. In Cuadernos de Doctrina Judicial de la Provincia de La Pampa. Santa Rosa: Poder Judicial de la Provincia de La Pampa, Vol VI No. 1, 2014.

DI PAOLA, María Eugenia; MACHAIN, Natalia. El Principio Precautorio en la República Argentina. In Derecho Ambiental. Revista Jurídica de Buenos Aires. Facultad de Derecho de la Universidad de Buenos Aires. Buenos Aires: Lexis Nexis, 2005.

ESAIN, José. El principio de prevención en la nueva ley general del ambiente 25.675. In Suplemento de Derecho Administrativo Revista Jurídica Lexis Nexis. Buenos Aires: Lexis Nexis, 01.09.04.

HERNÁNDEZ, Raúl. Tapón de Alonso. In El agua en La Pampa. Introducción a la problemática hídrica. Santa Rosa: Gobierno de La Pampa - CFI, Año 4, Nro. 3, 2013.

IURMAN, Daniel; ARAGÓN, Marcos; SÁNCHEZ, Ramón; ANCIA, 
Virginia. Variables a considerar para una estimación de las pérdidas económicas por causa de la salinización del Río Colorado y su cuantificación. Buenos Aires: CORFO Río Colorado - INTA Estación Experimental Agropecuaria Hilario Ascasubi - Ministerio de Agricultura, Ganadería y Pesca, 2007. Disponible en http://inta.gob.ar/documentos/variables-a-considerar-para-una-estimacionde-las-perdidas-economicas-por-causa-de-la-salinizacion-del-rio-coloradoy-su-cuantificacion Acceso 25 abr. 2017

MOYANO, Amílcar. Recursos hídricos provinciales compartidos. El caso del Río Colorado. In Revista de Derecho Ambiental. Buenos Aires: Lexis Nexis, $n^{\circ}$ 14, 2008.

QUIROGA LAVIÉ, Humberto; BENEDETTI, Miguel Ángel; CENICACELAYA, María de las Nieves. Derecho Constitucional Argentino. Buenos Aires: Editorial Rubinzal-Culzoni, 2001.

REGAZZOLI, Matías; MECA, Juan. Los organismos de cuencas hídricas como herramienta de solución de controversias interjurisdiccionales. In II Congreso Nacional de Derecho Agrario Provincial. La Plata: Facultad de Ciencias Jurídicas y Sociales, Universidad Nacional de La Plata, 2013. Disponible en http://sedici.unlp.edu.ar/bitstream/handle/10915/39556/Documento_comple to.Los\%20organismosdecuencas.pdf?sequence=1 Acceso 19 abr. 2017. 